\title{
ANATOMIA DA MADEIRA DE SCHWARTZIA BRASILIENSIS (CHOISY) BEDELL EX GIR.-CAÑAS (MARCGRAVIACEAE) ${ }^{1}$
}

\author{
JOÃO CARLOS FERREIRA DE MELO JÚNIOR² MAICK WILLIAN AMORIM ${ }^{3}$ \\ ÍGOR ABBA ARRIOLA ${ }^{4}$
}

\section{RESUMO}

O presente estudo descreve e ilustra a anatomia da madeira de Schwartzia brasiliensis (Marcgraviaceae), com base em material procedente da restinga de São Francisco do Sul, Santa Catarina, Brasil. Os caracteres anatômicos de destaque são: camadas de crescimento distintas, porosidade difusa, pontoações intervasculares alternas, fibras septadas, parênquima axial apotraqueal e paratraqueal, raios extremamente altos e heterogêneos, e inclusões minerais em células do raio e do parênquima axial.

Palavras-chave: anatomia do lenho, Marcgraviaceae, Schwartzia brasiliensis.

\section{ABSTRACT}

[Wood anatomy of Schwartzia brasiliensis (Choisy) Bedell ex Gir-Cañas (Marcgraviaceae)].

This study describes and illustrates the anatomy of the wood of Schwartzia brasiliensis (Marcgraviaceae), based on material from a sandbank in São Francisco do Sul, Santa Catarina, Brazil. The highlight of anatomical characters are: distinct growth rings, diffuse porosity, alternate intervessel pits, septated fibers, apotracheal and paratracheal axial parenchyma, extremely high and heterogeneous rays and mineral inclusions in ray cells and axial parenchyma cells.

Keywords: Marcgraviaceae, Schwartzia brasiliensis, wood anatomy.

\section{INTRODUÇÃO E REVISÃO DE LITERATU- RA}

Marcgraviaceae possui oito gêneros e cerca de 130 espécies de distribuição exclusivamente neotropical, desde o sul do México até o norte da Bolívia e o sul do Brasil (Giraldo-Cañas, 1999, 2007; Picca \& Giraldo-Cañas, 1999; Dressler, 2004). Os principais gêneros da família são: Marcgravia L. (65 spp.), Souroubea Aubl. (19 spp.), Marcgraviastrum (Wittm. ex Szyszy.) de Roon \& S. Dressler e Schwartzia Vell. (ambos com 15 spp.) (Dressler, 2009).

1 Recebido em 13-7-2016 e aceito para publicação em 12-9-2016.

2 Biólogo, Doutor, Professor Titular do Departamento de Ciências Biológicas, Laboratório de Anatomia e Ecologia Vegetal, Universidade da Região de Joinville, Joinville, Santa Catarina, Brasil. joao.melo@univille.br

3 Acadêmico, curso de Ciências Biológicas - Meio Ambiente e Biodiversidade, Departamento de Ciências Biológicas, Univ. da Região de Joinville, Joinville, Santa Catarina, Brasil. maickwamorim@gmail.com

4 Acadêmico, curso de Ciências Biológicas - Meio Ambiente e Biodiversidade, Departamento de Ciências Biológicas, Universidade da Região de Joinville, Joinville, Santa Catarina, Brasil. arriolaigor@gmail.com
Dentro desta família encontra-se o complexo Norantea (lato sensu), que abrange os gêneros Marcgraviastrum, Sarcopera Bedell, Norantea Aubl. (stricto sensu) e Schwartzia, anteriormente agrupados sob o mesmo gênero (de Roon \& Dressler, 1997; Giraldo-Cañas, 2002). Com a confirmação de que Norantea não é um gênero monofilético, e devido à heterogeneidade entre as espécies do grupo, estas foram segregadas em quatro gêneros (Ward \& Price, 2002; Giraldo-Cañas \& Fiaschi, 2005).

No Brasil ocorrem seis gêneros e, aproximadamente, 35 espécies; destas 11 são endêmicas das florestas brasileiras, com registros em todos os estados (Souza, 2015). Assim, o Brasil é o segundo país com a maior diversidade de Marcgraviaceae, ficando atrás apenas da Colômbia, que tem cerca de 60 espécies da família em sua flora (Giraldo-Cañas, 2004). Dentre os seis gêneros ocorrentes no Brasil, incluem-se Ruyschia Jacq. e Souroubea, além dos quatro gêneros do complexo Norantea (Giraldo-Cañas \& Fiaschi, 2005; Souza, 2015). O gênero 
Schwartzia distribui-se desde a Costa Rica, algumas ilhas no Caribe e Venezuela, até a Bolívia e o sul do Brasil, ocorrendo em áreas alagadas e florestas em diferentes estádios sucessionais, do nível do mar a $2500 \mathrm{~m}$ de altitude (Giraldo-Cañas, 2004). No Brasil, este gênero é representado por quatro espécies endêmicas: Schwartzia adamantium (Cambess.) Bedell ex. Gir.-Cañas, S. geniculatiflora GirCañas \& Fiaschi, S. jucuensis Gir.-Cañas e $S$. brasiliensis (Giraldo-Cañas, 2004; Souza, 2015). Destas, Schwartzia brasiliensis (Choisy) Bedell ex Gir.-Cañas destaca-se por apresentar ampla distribuição geográfica, marcada pela presença em 15 estados (Ferreira, 1995; Souza, 2015).

Na região Sul, a família Marcgraviaceae está representada nos estados de Santa Catarina e Paraná por Marcgravia polyantha Delpino e Schwartzia brasiliensis (Vibrans et al., 2013; Souza, 2015).

Schwartzia brasiliensis é encontrada nas regiões Nordeste (Alagoas, Bahia, Ceará, Paraíba, Pernambuco, Rio Grande do Norte, Sergipe), Centro-Oeste (Distrito Federal, Goiás), Sudeste (Espírito Santo, Minas Gerais, Rio de Janeiro, São Paulo) e Sul (Paraná, Santa Catarina), ocorrendo nos domínios fitogeográficos do Cerrado (matas de galeria e campos rupestres), Caatinga stricto senso e Floresta Atlântica (manguezais e restingas), do nível do mar a 1000m de altitude (Ferreira, 1995; GiraldoCañas, 2001; Giraldo-Cañas \& Fiaschi, 2005; Souza, 2015).

Conhecida pelos nomes vernaculares de cachimbeira, cachimbinho e agarrapé (Ferreira, 1995; Santos et al., 2009; Melo Júnior \& Boeger, 2015), Schwartzia brasiliensis é morfologicamente descrita como arbusto terrestre escandente de 6-25 $\mathrm{m}$ de altura e de ramos lisos a levemente estriados. As folhas, com pecíolo de $1,5 \mathrm{~cm}$ de comprimento, apresentam limbo obovado $(7-10 \times 4-6 \mathrm{~cm})$, coriáceo, de base obtusa a cuneada, ápice obtuso, com 3-6 pares de glândulas próximas da margem e 1 par de glândulas na base da lâmina. A inflorescência agre- ga 40-83 flores, em raque com $21-32 \mathrm{~cm}$ de comprimento. Os nectários, de 6-10 × 4-7 mm, variam de vináceos a roxos e localizam-se no terço proximal do pedicelo; cocleariformes, apresentam abertura circular com borda levemente revoluta e pedicelo de 3-6 mm de comprimento. As flores, subopostas, têm inserção pediceloflor reta, pedicelo de 1,5-3 cm de comprimento, bractéolas com cerca de $1 \times 1 \mathrm{~mm}$ comprimento, sépalas orbiculares amarelo-esverdeadas de 1-2 $\times$ cerca de $1 \mathrm{~mm}$, pétalas de 4-6 × 3-5 mm, obovadas, púrpura a vináceas, com ápice obtuso a levemente retuso, estames, 14 , com cerca de $1,5 \mathrm{~mm}$ de comprimento, adnatos às pétalas, antera vinácea ou amarelada, pistilo com cerca de $1,5 \mathrm{~mm}$ comprimento, e ovário com 4 ou 5 lóculos. Os frutos são globosos, apiculados, levemente rugosos, de 7-12 mm de diâmetro. As sementes, numerosas, semilunares, rugosas, reticuladas e escuro-brilhantes, medem 5-6 mm de comprimento por 1-1,5 mm de largura (Giraldo-Cañas, 2004; Teixeira et al., 2013).

Considerada importante sob o ponto de vista ecológico, como fornecedora de recursos para a avifauna (Sazima et al., 1993), a espécie $S$. brasiliensis ainda é pouco estudada. No âmbito da caracterização anatômica, tem-se registro de apenas um estudo relativo à anatomia foliar (Ferreira, 1982) e outro sobre a estrutura floral (Schönenberger et al., 2010). Neste sentido, o presente estudo tem como objetivo caracterizar a anatomia da madeira de Schwartzia brasiliensis (Marcgraviaceae), contribuindo com a ampliação dos conhecimentos sobre a espécie.

\section{MATERIAL E MÉTODOS}

O material botânico estudado é proveniente da formação arbustiva do ambiente de restinga, no Parque Estadual Acaraí, localizado no município de São Francisco do Sul, Santa Catarina (coordenadas $26^{\circ} 17^{\prime} \mathrm{S}$ e $48^{\circ} 33^{\prime} \mathrm{W}$ ) (Figura 1). Este parque é tido como o maior remanescente de restinga em área contínua no Estado, e reconhecido como área de prioridade extremamente alta para a conservação da biodiversidade 

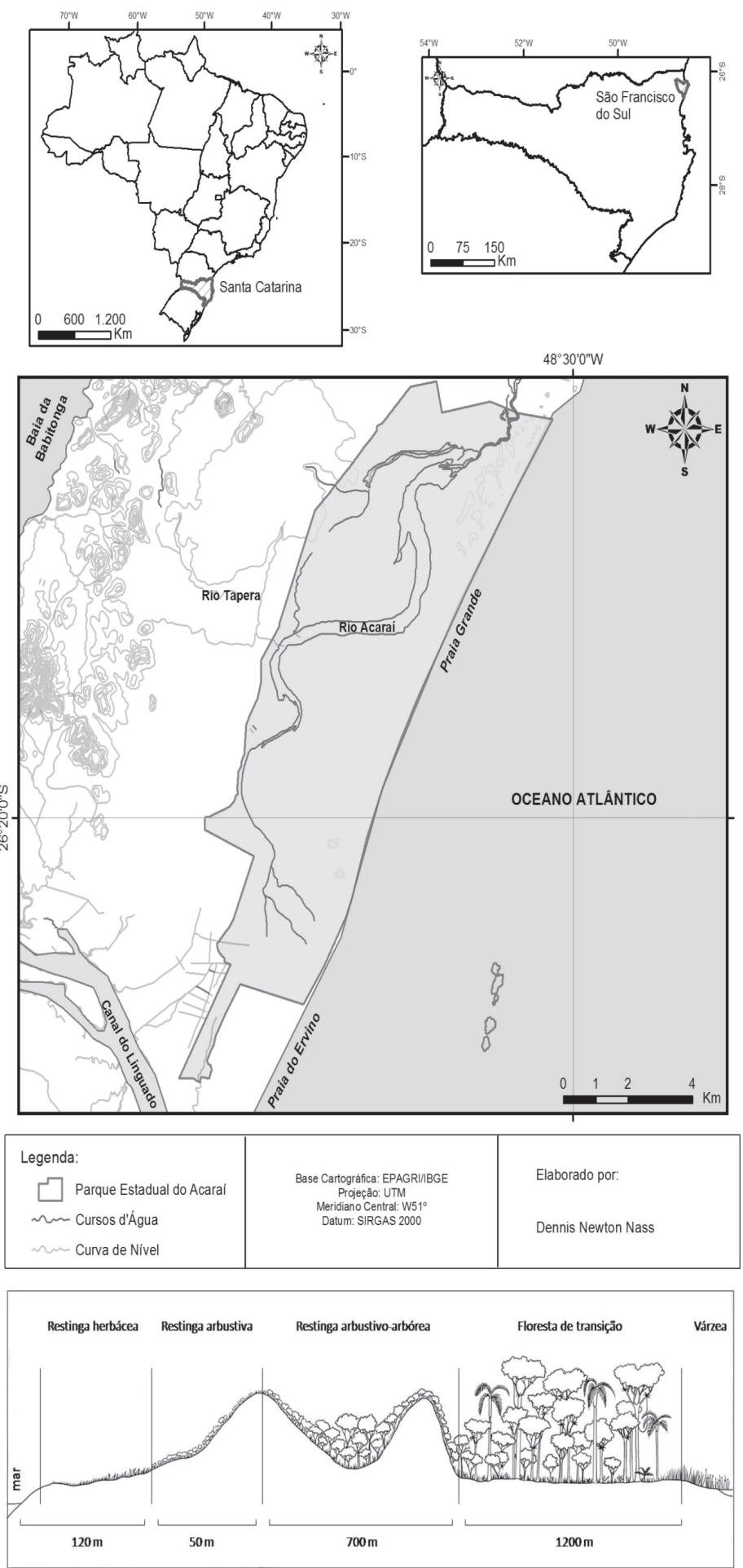

FIGURA 1 - Localização do Parque Estadual Acaraí e da formação de restinga arbustiva (perfil), área de coleta dos indivíduos de Schwartzia brasiliensis para a caracterização anatômica da madeira. Fonte: Melo Jr. (2015). 
(PROBIO, 2003). O clima, fortemente influenciado pela umidade marítima, é mesotérmico sem estação seca definida, com verões quentes (Cfa, segundo a classificação de Köppen) e índices pluviométricos médios de $1.874 \mathrm{~mm}$ ao ano (Knie, 2002). O relevo, de típica planície costeira, tem 6.667 ha recobertos por vegetação de restinga das formações herbácea, arbustiva, arbustivo-arbórea e floresta de transição, além de outras formações menos representativas, como floresta submontana, várzeas e manguezais (FATMA, 2008). O solo da formação arbustiva é classificado como Espodossolo Ferrihumilúvico (EPAGRI, 2002).

No referido ambiente foram coletadas amostras de madeira da base do caule do perfilho de maior diâmetro, pertencente a cinco indivíduos amostrais de Schwartzia brasiliensis. Corpos de prova foram confeccionados para o cozimento em água glicerinada e posterior secsagem em micrótomo de deslize Zeiss, com navalha tipo $\mathrm{C}$, nos planos transversal, longitudinal radial e longitudinal tangencial (Johansen, 1940; Sass, 1951). Em seguida, os cortes foram clarificados em hipoclorito de sódio, lavados em água destilada, corados com safrablau, desidratados em série etílica crescente (Kraus \& Arduin, 1997) e montados em resina sintética do tipo verniz vitral (Paiva et al., 2006). Macerações foram preparadas por meio da solução de Franklin, modificada por Kraus \& Arduin (1997), para posterior biometria de vasos (comprimento e diâmetro tangencial) e fibras (espessura da parede), $\operatorname{com} n=30$. As microfotografias foram capturadas com fotomicroscópio Olympus CX-31. As mensurações foram feitas por meio do software Dino Eye 2.0. A caracterização anatômica foi baseada na terminologia do IAWA Committee (1989). Para todos os atributos quantitativos da madeira foram calculados as médias e os respectivos desvios-padrão.

\section{RESULTADOS}

A anatomia da madeira de Schwartzia brasiliensis é seguir descrita e ilustrada.
Camadas de crescimento: distintas, demarcadas por espessamento radial da parede de fibras no lenho tardio.

Vasos: porosidade difusa, sem arranjo definido; predominantemente solitários, poucos múltiplos de 2-5, raros racemiformes; diâmetro tangencial de 60-104 $\mu \mathrm{m}(78,08 \pm 11,78)$; frequência de 11-16 $(17,49 \pm 3,95)$ vasos $/ \mathrm{mm}^{2}$; comprimento de 434-1132 $\mu \mathrm{m}(814,99 \pm 133,82)$; placas de perfuração simples; pontoações intervasculares alternas, areoladas, medianas, de 4,0-6,8 $\mu \mathrm{m}(4,74 \pm 0,67)$; pontoações radiovasculares com aréolas reduzidas, aparentemente simples; redondas ou angulares.

Fibras: libriformes, septadas; comprimento de 1043-1400 $\mu \mathrm{m}(1236,15 \pm 88,92)$; largura de $27-41 \mu \mathrm{m}(33,89 \pm 4,48)$; pontoações simples a diminutas areoladas (vista longitudinal tangencial); espessura da parede de fibras, de fina a espessa.

Parênquima axial: apotraqueal difuso; paratraqueal escasso; séries parenquimáticas com 1-4 células.

Raios: 1-3seriados; extremamente altos; largura de 20,87-31,73 $\mu \mathrm{m}(25,33 \pm 3,20)$; heterogêneos, com corpo formado por células procumbentes e quatro camadas de células marginais eretas ou quadradas.

Inclusões minerais: ráfides em células eretas de raio; cristais prismáticos em câmaras subdivididas do parênquima axial.

\section{DISCUSSÃO}

As características anatômicas microscópicas descritas para Schwartzia brasiliensis são, de forma geral, aquelas preconizadas para a família Marcgraviaceae (Metcalfe \& Chalk 1950); alguns atributos da madeira, entretanto, são discordantes.

A demarcação de camadas de crescimento por espessamento das fibras, observadas neste estudo, opõe-se ao limite indistinto ou mesmo ausente, citado para diferentes espécies dos gêneros Marcgravia, Marcgraviastrum, Norantea, Ruyschia, Sarcopera, Schwartzia e Souroubea, 

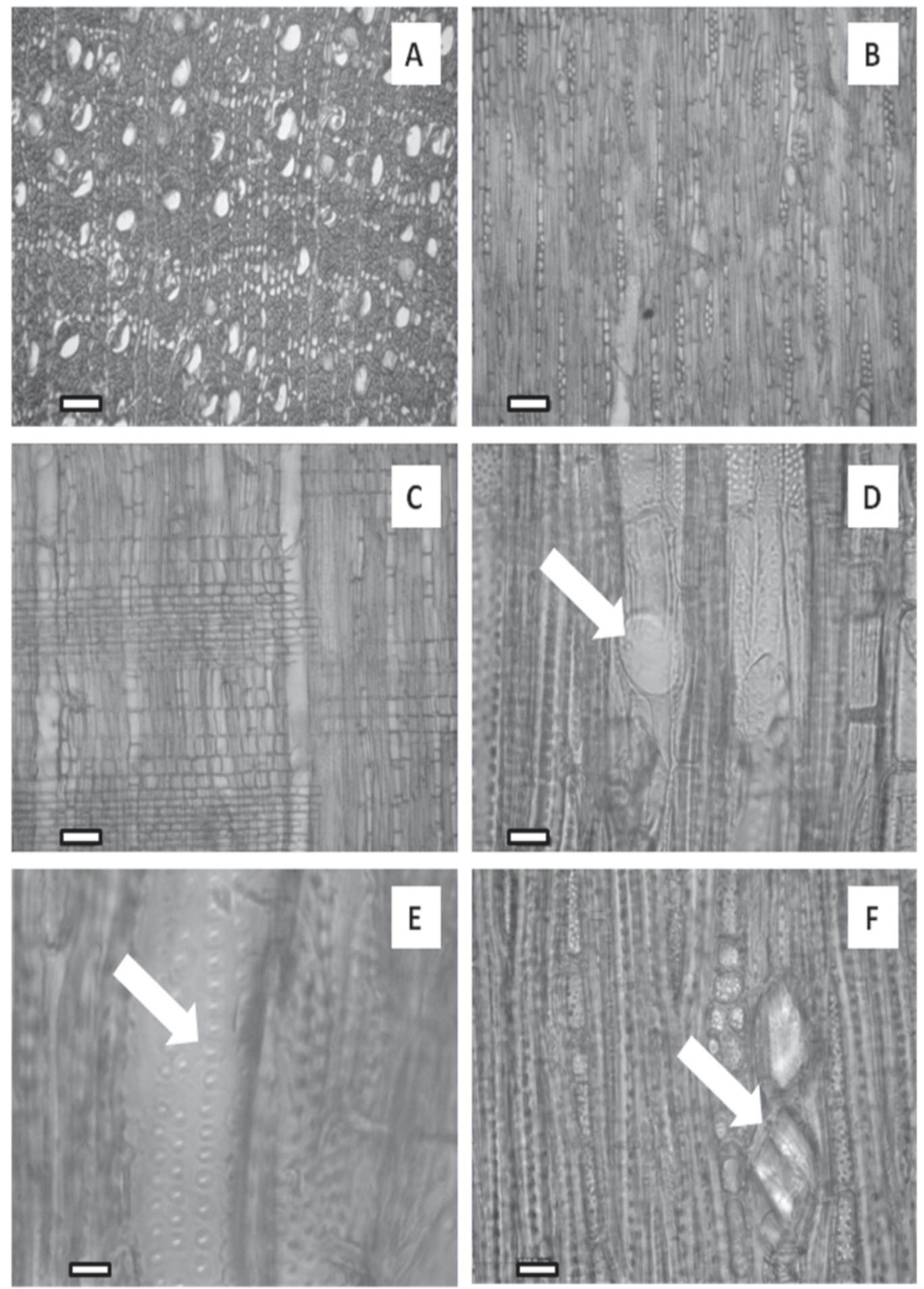

FIGURA 2 - Anatomia da madeira de Schwartzia brasiliensis (Marcgraviaceae). A - Porosidade difusa, em secção transversal. B - Raios predominantemente unisseriados, em secção longitudinal tangencial. C - Raios heterogêneos em secção longitudinal radial. D - Placa de perfuração simples (seta). E - Pontoações intervasculares areoladas (seta). F - Cristais prismáticos em células de parênquima axial (seta). Barras de escala = $100 \mu \mathrm{m}(\mathrm{A}-\mathrm{D}, \mathrm{F})$ e $10 \mu \mathrm{m}(\mathrm{E})$. 
estudadas no contexto da ordem Ericales por Lens et al. (2005). Estudo realizado com 419 espécies lenhosas, pertencentes às 22 famílias mais representativas da flora brasileira, apontou a presença de camadas de crescimento distintas em $48 \%$ das espécies estudadas, o que revela uma relação entre atividade cambial e climas úmidos tropicais e a existência de marcadores de crescimento em muitas espécies tropicais (Alves \& Angyalossy-Alfonso, 2000). Em regiões tropicais e subtropicais, a presença de camadas de crescimento, sejam elas anuais ou não, decorrem da alternância de condições ambientais, com períodos favoráveis e/ou desfavoráveis, associadas às condições ecológicas de crescimento dessas árvores (Botosso, 2011). A região Sul do Brasil apresenta chuvas abundantes e bem definidas durante todo o ano, que explicam a umidade elevada e quase constante, e grande oscilação térmica anual, com verões quentes e invernos frios. Esta variação térmica é apontada como responsável pela formação de camadas de crescimento em diversas espécies vegetais (Alves \& Angyalossy-Alfonso, 2000).

A porosidade difusa, observada na madeira de Schwartzia brasiliensis, é característica relatada como prevalente em $84 \%$ das espécies tropicais estudadas por Alves \& AngyalossyAlfonso (2000), juntamente com a predominância de vasos solitários e múltiplos, presentes em cerca de $76 \%$ dessas espécies, e de placas de perfuração simples (95\%), sendo assim consideradas, pelos autores, como caracteres comuns na flora do Brasil. No contexto da flora sul-brasileira, a prevalência da porosidade difusa em 79 espécies nativas do Rio Grande do Sul também foi apontada como característica relacionada ao posicionamento latitudinal dos ecossistemas deste estado (Santos \& Marchiori, 2010).

$\mathrm{Na}$ família Marcgraviaceae se observa grande variação no diâmetro tangencial de vasos, que se estende de $71 \mu \mathrm{m}$, para Schwartzia spiciflora, $98 \mu \mathrm{m}$ para Schwartzia costaricensis, $124 \mu \mathrm{m}$ para Schwartzia adamantium e $234 \mu \mathrm{m}$ para Schwartzia diaz-piedrahitae (Lens et al., 2005), corroborando os valores observados para
Schwartzia brasiliensis no presente estudo, que apresenta vasos pequenos, entre 50-100 $\mu \mathrm{m}$. Vasos de diâmetro reduzido podem resultar de baixa disponibilidade hídrica, característica do ambiente de coleta dos espécimes estudados (Melo Jr., 2015). De fato, as características das células de condução de água, tais como a disposição, frequência, comprimento, diâmetro, espessura de parede e tamanho das pontoações, refletem o equilíbrio entre eficiência e segurança no transporte hídrico, resultando no crescimento ideal da árvore. A ideia central é de que as árvores precisam ajustar ano-a-ano a estrutura do xilema às variações do ambiente (JeongWook et al., 2013). Assim, a disponibilidade de água em ambientes com diferentes níveis de suprimento deste recurso, tanto para condições favoráveis quanto para condições limitantes, exerce uma influência direta sobre as características dos elementos de vaso, o que tem sido reportado por vários estudos (Carlquist, 1966, 1980; Baas, 1976; Baas et al., 1983; Baas \& Carlquist, 1985; Barajas-Morales, 1985; Fahn et al., 1986; Chimelo \& Mattos-Filho, 1988; Alves \& Angyalossy-Alfonso, 2000; Melo Júnior et al., 2011).

As fibras septadas, relatadas como característica da família Marcgraviaceae (Record \& Hess, 1943; Lens et al., 2005), podem ter função de armazenamento de substâncias, tal como ocorre com as células parenquimáticas (Chalk, 1989). A presença de fibras septadas no lenho de Schwartzia brasiliensis pode estar relacionada ao armazenamento de água e substâncias de reserva, uma vez que as condições nutricionais e hídricas do ambiente de coleta dos espécimes aqui estudados são limitantes ao crescimento e desenvolvimento da vegetação (Melo Júnior \& Boeger, 2015).

Os tipos de parênquima axial observados em Schwartzia brasiliensis coincidem com os reportados por Metcalfe \& Chalk (1950) para a família Marcgraviaceae. Em contraposição, a presença de parênquima axial apotraqueal difuso não é referida por Record \& Hess (1943), o que sugere a necessidade de ampliar os estudos 
anatômicos da madeira, incluindo outras espécies do gênero Schwartzia. Para Chalk (1937), o parênquima axial apotraqueal é padrão não especializado, que evidencia característica mais primitiva.

O padrão de raios observado em Schwartzia brasiliensis está de acordo com o citado por Metcalfe \& Chalk (1950), Record \& Hess (1943) e Lens et al. (2005) para a família Marcgraviaceae. Apesar de ser um atributo funcional no lenho das espécies (Pérez-Harguindeguy, 2013), as análises das tendências ecológicas relacionadas ao tamanho e ao tipo de raio ainda são muito especulativas nos diferentes sistemas ecológicos (Baas, 1982) e não mostram um padrão claro para as espécies brasileiras (Alves \& Angyalossy-Alfonso, 2002). Por outro lado, estudo realizado com 26 espécies arbóreas de uma comunidade florestal de planície menciona a ocorrência de raios 1-3seriados como um padrão dessas espécies, que pode exibir mudanças similares às do parênquima axial em espécies tropicais (Barros et al., 2006).

A presença de inclusões minerais é comum, mas não característica em famílias da ordem Ericales (Lens et al., 2005). A presença de ráfides em células eretas de raios é comum nos gêneros Marcgravia e Souroubea e inconstantes nos demais gêneros da familia Marcgraviaceae (Record \& Hess, 1943). Segundo Metcalfe \& Chalk (1950), a precipitação de cristais pode funcionar como reserva de substâncias a serem incorporadas no ciclo metabólico quando necessárias, ou como proteção à herbivoria, sendo mais comuns em plantas de ambientes secos (Barajas-Morales, 1985).

\section{REFERÊNCIAS BIBLIOGRÁFICAS}

ALVES, E.S.; ANGYALOSSY-ALFONSO, V. Ecological trends in the wood anatomy of some Brazilian species. I: Growth rings and vessels. IAWA Journal, v. 21, p. 3-30, 2000.

ALVES, E.S.; ANGYALOSSY-ALFONSO, V. Ecological trends in the wood anatomy of some Brazilian species. 2: Axial parenchyma, rays and fibers. IAWA Journal, v. 23, n. 4, p. 391-418, 2002.
BAAS, P. Some functional and adaptative aspects of vessel member morphology. Leiden Botanical Series, v. 3, 157-181, 1985.

BAAS, P.; CARLQUIST, S. A comparison of the ecological wood anatomy of the floras of Southern California and Israel. IAWA Bulletin New Series, v. 6, n.4, p. 141-159, 1985.

BAAS, P.; WERKER, E.E.; FAHN, A. Some ecological trends in vessel characters. IAWA Bulletin New Series, v. 4, p. 141-159, 1983.

BARAJAS-MORALES, J. Wood structural differences between trees of the tropical forests in Mexico. IAWA Bulletin, v. 6, n.4, p. 355-364, 1985.

BARROS, C.F.; MARCON-FERREIRA, M.L.; CALLADO, C.H.; LIMA, H.R.P.; CUNHA, M.; MARQUETE, O.; COSTA, C.G. Tendências ecológicas na anatomia da madeira de espécies da comunidade arbórea da Reserva Biológica de Poço das Antas, Rio de Janeiro, Brasil. Rodriguésia, v. 57, n. 3, p. 443-460, 2006.

BOTOSSO, P.C. Identificação macroscópica de madeiras: guia prático e noções básicas para o seu reconhecimento. Colombo: Embrapa Florestas, 2011. $65 \mathrm{p}$.

CARLQUIST, S. Wood anatomy of Compositae: a summary with comments on factors controlling wood evolution. Aliso, v. 6, n.2, p. 25-44, 1966.

CARLQUIST, S. Further concepts in ecological wood anatomy, with comments on recent work in wood anatomy and evolution. Aliso, v. 9, n.4, p. 499553, 1980.

CHALK, L. The phylogenetic value of certain anatomical features of Dicotyledonous woods. Annals of Botany, v.1, n.3, p. 409-428, 1937.

CHALK, L. Fibres. In: Anatomy of the Dicotyledons: Wood structure and conclusion of the general introduction (C.R. Metcalfe \& L. Chalk, eds.). Oxford: Oxford University Press, 1989.

CHIMELO, J.P.; MATTOS-FILHO, A. Observações preliminares na estrutura da madeira de cinco espécies de folhosas de diferentes locais do Brasil. São Paulo: International Union of Forest Research Organizations, 1988. 117 p.

DE ROON, A.; DRESSLER, S. New taxa of Norantea Aubl. s.l. (Marcgraviaceae) from Central America and adjacent South America. Bot. Jahrb. Syst., v. 119, p. 327-335, 1997.

DRESSLER, S. Marcgraviaceae. In: Flowering Plants of the Neotropics (N. Smith; S.A. Mori; 
A. Henderson; D.W. Stevenson; S.V. Heald, eds.). Princeton: Princeton University Press, 2004. p. 236-238.

DRESSLER, S. Neotropical Marcgraviaceae. In: Neotropikey - Interactive key and information resources for flowering plants of the Neotropics. W. Milliken; B. Klitgård; A.Baracat., 2009. Available from: http://www.kew.org/science/ tropamerica/neotropikey/families/ Marcgraviaceae.htm (acessed 13 July 2016).

EPAGRI. Mapa de solos: unidade de planejamento regional litoral norte catarinense. Florianópolis: Empresa de Pesquisa Agropecuária e Extensão Rural de Santa Catarina, 2002.

FAHN, A.; WERKER, E.; BAAS, P. Wood anatomy and identification of trees and shrubs from the Israel and adjacent regions. Jerusalem: The Israel Academy of Sciences of Humanities, 1986. $82 \mathrm{p}$.

FATMA. Plano de manejo do Parque Estadual do Acaraí. Curitiba: FATMA, 2008.

FERREIRA, G. Anatomía foliar de Norantea brasiliensis Choisy (Marcgraviaceae). Arq. Jard. Bot. Rio de Janeiro, v. 26, p. 87-94, 1982.

FERREIRA, G. Estudo taxonômico das espécies brasileiras do gênero Norantea Aublet (Marcgraviaceae). Arq. Jard. Bot. Rio de Janeiro, v. 33, p. 9-53, 1995.

GIRALDO-CAÑAS, D.; FIASCHI，P. Las Marcgraviaceae (Ericales) de Brasil: Las especies del complejo Norantea. Caldasia, v. 27, n. 2, p. 173-194, 2005.

GIRALDO-CAÑAS, D. Las Marcgraviaceae de la Amazonia colombiana: estúdio preliminar sobre su diversidad, distribución y fitogeografía. Darwiniana, v. 37, p. 15-24, 1999.

GIRALDO-CAÑAS, D. Schwartzia braziliensis (Marcgraviaceae), nueva combinación. Caldasia, v. 23, n. 1, p. 341-342, 2001.

GIRALDO-CAÑAS, D. Novedades taxonómicas y corológicas en Marcgraviastrum, Sarcopera y Schwartzia (Marcgraviaceae) de Sudamérica. Hickenia, v. 3, n. 32, p. 119-123, 2002.

GIRALDO-CAÑAS, D. Las especies del género Schwartzia (Complejo Norantea, Marcgraviaceae) en Brasil. Darwiniana, v. 42, n.1-4, p. 169-175, 2004.
GIRALDO-CAÑAS, D. Un nuevo género de la familia neotropical Marcgraviaceae (Ericales) y circunscripción del complejo Norantea. Caldasia, v. 29, p. 203-217, 2007.

IAWA Committee. List of microscopic features for hardwood identification. IAWA Bulletin, v. 10, p. 219-332, 1989.

JEONG-WOOK, S.; ECKSTEIN, D.; OLBRICH, A.; JALKANEN, R.; SALMINEN, H.; SCHMITT, U.; FROMM, J. Climate control of wood formation: illustrated for Scots Pine at its Northern distribution limit. In: FROMM, J. Cellular aspects of wood formation. Springer, 2013. p. 159-186.

JOHANSEN, D.A. Plant microtechnique. London: McGraw-Hill Company Inc, 1940.

KNIE, J.L.W. (org.). Atlas ambiental da região de Joinville: complexo hídrico da Baía da Babitonga. FATMA/GTZ, Florianópolis, 2002.

KRAUS, J.E.; ARDUIN, M. Manual básico de métodos em morfologia vegetal. Rio de Janeiro: EDUR, 1997. 198 p.

LENS, F.; DRESSLER, S.; JANSEN, S.; VAN EVELGHEM, L.; SMETS, E. Relationships within balsaminoid Ericales: a wood anatomical approach. American Journal of Botany, v. 92, p. 941-953, 2005. (doi:10.3732/ajb.92.6.941)

MELO JÚNIOR, J.C.F. Plasticidade fenotípica $e$ diversidade funcional de comunidades florísticas em gradiente edáfico na Restinga do Parque Estadual do Acaraí, São Francisco do Sul/SC. Curitiba: Universidade Federal do Paraná, 2015. Tese (Doutorado). 168 p.

MELO JÚNIOR, J.C.F.; BOEGER, M.R.T. Riqueza, estrutura e interações edáficas em um gradiente de restinga do Parque Estadual do Acaraí, estado de Santa Catarina, Brasil. Hoehnea, v. 42, n. 2, p. 207-232, 2015.

MELO JÚNIOR, J.C.F.; CECCANTINI, G.; BONA, C. Anatomia ecológica do lenho de Copaifera langsdorffii Desf. (Leguminosae) distribuída em diferentes condições edáficas do cerrado sulbrasileiro. Iheringia, Série Botânica, v. 66, p. 189-200, 2011.

METCALFE, C.R.; CHALK, L. Anatomy of Dicotyledons. Vols. I and II. Oxford: Clarendon Press, 1950. 
PAIVA, J.G.A.; FANK-DE-CARVALHO, S.M.; MAGALHÃES, M.P.; GRACIANO-RIBEIRO, D. Verniz vitral incolor 500: uma alternativa de meio de montagem economicamente viável. Acta Bot. Bras., v. 20, n. 2, p. 257-264, 2006.

PÉREZ-HARGUINDEGUY，N.; DÍAZ，S.; GARNIER, E.; LAVOREL, S.; POORTER, H.; JAUREGUIBERRY, P.; BRET-HARTE, M.S.; CORNWELL, W.K.; CRAINE, J.M.; GURVICH, D.E.; URCELAY, C.; VENEKLAAS, E.J.; REICH, P.B.; POORTER, L.; WRIGHT, I.J.; RAY, P.; ENRICO, L.; PAUSAS, J.G.; DE VOS, A.C.; BUCHMANN, N.; FUNES, G.; QUÉTIER, F.; HODGSON, J.G.; THOMPSON, K.; MORGAN, H.D.; TER STEEGE, H.; VAN DER HEIJDEN, M.G.A.; SACK, L.; BLONDER, B.; POSCHLOD, P.; VAIERETTI, M.V.; CONTI, G.; STAVER, A.C.; AQUINO, S.; CORNELISSEN, J.H.C. New handbook for standardized measurement of plant functional traits worldwide. Australian Journal of Botany, v. 61, p. 167-234, 2013.

PICCA, P.; GIRALDO-CAÑAS. D. Una nueva especie de Marcgravia (Marcgraviaceae) de la Amazonia colombiana. Hickenia, v. 2, p. $293-$ 298, 1999.

PROBIO. Áreas prioritárias para a conservação, utilização sustentável e repartição de benefícios da biodiversidade brasileira. Brasília: Ministério do Meio Ambiente, 2003.

RECORD, S.J.; HESS, R.W. Timbers of the New World. New Haven: Yale Univ. Press, 1949. 640 p.

SANTOS, M.G.; FEVEREIRO, P.C.A.; REIS, G.L.; BARCELOS, J.I.; NEY, F.M.M.A. Plantas da restinga: potencial econômico. Rio de Janeiro: Technical Books, 2009. 139 p.
SANTOS, S.R.; MARCHIORI, J.N.C. Tendências anatômicas na flora sul-riograndense. 1. Elementos de vaso. Balduinia, v. 21, p. 1-14, 2010.

SASS, J. E. Botanical microtechnique. Ames: Iowa State College Press, 1951. 228p.

SAZIMA, I.; BUZATO, S.; SAZIMA, M. The bizarre inflorescence of Norantea brasiliensis (Marcgraviaceae): visits of hovering and perching birds. Bot. Acta, v. 106, n. 6, p. 507-513, 1993.

SCHÖNENBERGER, J.; VON BALTHAZAR, M.; SYSTMA, K.J. Diversity and evolution of floral structure among early diverging lineages in the Ericales. Phil. Trans. R. Soc. B., v. 365, p. 437-448, 2010.

SOUZA, V.C. Marcgraviaceae. In: Lista de Espécies da Flora do Brasil. Rio de Janeiro: Jardim Botânico do Rio de Janeiro. 2015. Available from: http://floradobrasil.jbrj.gov.br/jabot/ floradobrasil/FB158 (acessed 13 july 2016).

TEIXEIRA, M.D.R.; FIASCHI, P.; AMORIM, A.M. Flora da Bahia: Marcgraviaceae. Sitientibus: Série Ciências Biológicas, v. 13, 2013. (doi 10.13102/scb219.)

VIBRANS, A.C.; SEVEGNANI, L.; GASPER, A.L.; LINGNER, D.V. Inventário Florístico Florestal de Santa Catarina: Floresta Ombrófila Densa. Blumenau: Edifurb, 2013. v. 4. 576 p.

WARD, N.; PRICE, R. Phylogenetic relationships of Marcgraviaceae: Insights from three chloroplast genes. Syst. Bot., v. 27, p. 149-160, 2002.

ZENID, G.J.; CECCANTINI, G.C.T. Identificação macroscópica de madeiras. São Paulo: Laboratório de Madeira e Produtos Derivados; Centro de Tecnologia de Recursos Florestais; Instituto de Pesquisas Tecnológicas do Estado de São Paulo - IPT, 2007. 